\title{
A Survey of Internal Medicine Interns Regarding the Most Useful Topics to Include in an Internal Medicine Track of a "Get Ready for Residency Boot Camp" Course
}

\author{
Bhavya Varma $^{1} \cdot$ Leonid Mirson $^{1} \cdot$ Rachel Vanderberg $^{1,2}$ (D) $\cdot$ Anna K. Donovan ${ }^{1,2}$ \\ Accepted: 12 October 2020 / Published online: 21 October 2020 \\ (C) International Association of Medical Science Educators 2020
}

\begin{abstract}
In the last decade, boot camp residency preparatory courses for fourth-year medical students have become increasingly popular in medical schools across the USA; however, the curricular content of these courses varies widely. The authors surveyed internal medicine interns at a large academic medical center regarding clinical and non-clinical topics that would be useful for an internal medicine residency preparatory curriculum. The response rate was 79\% (64/81). A rational approach to antibiotics (42\%) and electrolyte management (41\%) were the most frequent clinical topics and cross-cover (69\%) was the most frequent non-clinical topic selected by interns.
\end{abstract}

Keywords Transition to residency $\cdot$ Boot camp $\cdot$ Internal medicine

\section{Background}

Several studies suggest that incoming interns lack clinical and professional skills that residency program directors expect interns to have mastered during medical school [1-5]. Over the last decade, medical educators have created residency preparatory courses (boot camps) to bolster the skills of fourth-year medical students (MS4s) about to enter residency. As of 2018, 71 US medical schools had their own boot camps [6]. Institutions took individualized approaches in developing boot camps and boot camp curricula are not standardized across institutions [7-12]. To our knowledge, prior boot camp

Prior Presentation Virtually presented as poster presentation at Society of General Internal Medicine Annual Meeting, Birmingham, Alabama 2020. Accepted as poster presentation to UPMC Department of Medicine Research Day, Pittsburgh, Pennsylvania 2020, however meeting cancelled due to COVID-19.

Rachel Vanderberg

vanderbergrh@upmc.edu

1 Division of General Internal Medicine, UPMC Montefiore Hospital, University of Pittsburgh School of Medicine, Suite 933W, 200

Lothrop St., Pittsburgh, PA 15213, USA

2 Division of General Internal Medicine, University of Pittsburgh Medical Center, Pittsburgh, PA, USA curricula did not incorporate interns' perspectives about what topics are most helpful in such a course.

The University of Pittsburgh School of Medicine developed a MS4 boot camp in 2019 for implementation in March 2020. The course includes a general curriculum for all students as well as specialty specific tracks including internal medicine, emergency medicine, obstetrics and gynecology, pediatrics, and psychiatry (general surgery has a separate boot camp course). The general curriculum includes standardized patient sessions with a focus on communication, simulation of medical emergencies, large-group didactic sessions on a variety of topics (i.e., financial strategies, wellness, code status, pain management), and hands-on practice of basic skills like drawing blood with emergency department nurses. As the first step in developing the internal medicine (IM) boot camp curriculum, we conducted a needs assessment [12]. As part of the needs assessment, we reviewed curricula of existing boot camps and reviewed surveys of program directors regarding necessary skills for incoming interns $[7-11,13$, 14]. Additionally, we aimed to incorporate the intern perspective in our needs assessment by surveying internal medicine interns regarding which topics should be emphasized in this new boot camp curriculum. Using this approach, we intended for the curriculum to be anchored in the practical experience of interns in addition to medical education theory and expert opinion. As interns have 
recently experienced the transition from medical school to residency, they can provide unique and valuable input by identifying deficits in their undergraduate medical education. The University of Pittsburgh Institutional Review Board (IRB \#2003005) determined that this study is exempt.

\section{Activity}

We surveyed a convenience sample of IM interns from 44 accredited US medical schools in October of 2019 regarding the content areas that would be most useful in the IM track of the boot camp course.

Prior to the survey, we provided interns with a brief introduction to the curricular project. Prior to the survey, we also provided interns with an overview of topics included in the general curriculum (Table 1). The survey was voluntary and anonymous. The survey asked interns to examine a list of clinical (medical knowledge) topics and a list of non-clinical (communication, professionalism, patient care, and system-based practice) topics listed in Table 2. They were instructed to circle the three most useful topics from each list for inclusion in the IM track curriculum. The survey also had an optional free response section eliciting suggestions for one additional clinical and non-clinical topic. The list of topics presented to the interns was developed through literature review and local expert clinician educator faculty input. We excluded topics already included in the general curriculum.

\section{Results and Discussion}

There was a $79 \%$ response rate (64/81). The survey responses are shown in Table 2 . The most frequently identified useful clinical topics included rational approach to antibiotics (27/64, $42 \%)$; electrolyte management $(26 / 64,41 \%)$; inpatient diabetes management $(25 / 64,39 \%)$; and acid-base disorders (24/ $64,38 \%$ ). Clinical free text responses included acute pain, altered mental status, and critical care topics (i.e., respiratory failure and septic shock). The most frequently identified useful non-clinical topics included cross-cover $(44 / 64,69 \%)$; responding to difficult or offensive patients $(31 / 64,48 \%)$; giving and receiving feedback $(24 / 64,38 \%)$; and adult learning theory $(23 / 64,36 \%)$. Non-clinical free text responses included time management/organization tips and disposition/ discharge options.

The IM track consisted of 12 90-min workshops delivered over 1 month by both generalists and specialists. We incorporated the top four clinical and top four non-clinical topics identified by IM interns into the IM track of the boot camp course. We also included acute pain, altered mental status, time management/organizational tips, and disposition/ discharge options which were identified in the free response section. The workshops were lecture based with interactive components. The curriculum was mostly delivered over Zoom given the COVID-19 pandemic. Two workshops utilized a flipped classroom approach.

We strove to address the discrepancy between expected and actual skills of new interns, while also providing interns with a clinically high-yield, practical boot camp experience by including intern perspectives into the development of our boot

Table 1 Topics included in the general boot camp curriculum

\begin{tabular}{|c|c|}
\hline Clinical topics & Non-clinical topics \\
\hline Lecture & Lecture \\
\hline $\begin{array}{l}\text { - Pain management } \\
\text { - Informed consent } \\
\text { - Decision-making capacity } \\
\text { - Intravenous access }\end{array}$ & $\begin{array}{l}\text { - Wellness in residency } \\
\text { - Sleep } \\
\text { - Financial strategies } \\
\text { - Learning to teach (working with medical students) } \\
\text { - Working with consultants } \\
\text { - Medicine and media } \\
\text { - Sign out process/transitions of care }\end{array}$ \\
\hline \multicolumn{2}{|l|}{ Simulation activities } \\
\hline $\begin{array}{l}\text { - Cardiology_acute myocardial infarction, hypotension, cardiac arrest, hypertensive emergency } \\
\text { - Pulmonology_-spontaneous pneumothorax, pulmonary embolism with contrast allergy, severe } \\
\text { shortness of breath with tracheostomy } \\
\text { - Neurology_altered mental status, seizure, cerebrovascular accident, vertigo, closed head injury } \\
\text { - Infectious disease - meningitis, fever, sepsis, otitis externa, exudative pharyngitis } \\
\text { - Women's health — ruptured ectopic pregnancy, pelvic inflammatory disease with tubo-ovarian } \\
\text { abscess, appendicitis in a pregnant female } \\
\text { - Miscellaneous: code status, death, violent patient, hyperkalemia, fall from bed, kidney stone, } \\
\text { gastrointestinal bleed with coagulopathy }\end{array}$ & \\
\hline
\end{tabular}


Table 2 Intern survey responses regarding top three clinical and non-clinical topics to include in a fourth-year medical student residency preparatory course or boot camp

\begin{tabular}{|c|c|c|c|}
\hline Clinical topics & $n=64(\%)$ & Non-clinical topics & $n=64(\%)$ \\
\hline Rational approach to antibiotics & $27(42)$ & Cross-cover & $44(69)$ \\
\hline Electrolyte management & $26(41)$ & How to respond to "difficult" or offensive patients & $31(48)$ \\
\hline Diabetes inpatient management & $25(39)$ & How to give and receive feedback & $24(38)$ \\
\hline Acid-base status & $24(38)$ & Adult learning theory—strategies for effective teaching and learning & $23(36)$ \\
\hline Detox/withdrawal & $16(25)$ & Notes and presentations & $22(34)$ \\
\hline Congestive heart failure & $15(23)$ & Interdisciplinary care & $22(34)$ \\
\hline Cirrhosis & $12(19)$ & Social determinants of health & $8(12)$ \\
\hline End of life care & $11(17)$ & Mentoring & $8(12)$ \\
\hline Diabetes outpatient management & $6(9)$ & How to respond to sexual harassment from patients & $5(8)$ \\
\hline Asthma/Chronic obstructive pulmonary disease & $5(8)$ & Working with a translator & $2(3)$ \\
\hline High value care & $5(8)$ & & \\
\hline Constipation & $5(8)$ & & \\
\hline Outpatient management of substance use disorder & $4(6)$ & & \\
\hline Hypertension & $4(6)$ & & \\
\hline Approach to abnormal liver function tests & $3(5)$ & & \\
\hline Anemia & $1(1)$ & & \\
\hline Smoking cessation & $1(1)$ & & \\
\hline $\begin{array}{l}\text { LGBTQ (lesbian, gay, bisexual, transgender } \\
\text { and queer or questioning) healthcare }\end{array}$ & $1(1)$ & & \\
\hline Depression/anxiety & $1(1)$ & & \\
\hline
\end{tabular}

$n$, number of interns who circled this response. Interns were asked to circle three topics they felt were most important

camp curriculum. In addition, given the breadth of medical schools in our intern class, we believe our results can inform the development or revision of boot camps at other institutions. There are several limitations to our study. Despite the instructions to circle three topics, some interns circled fewer than three or more than three topics on the survey. With regard to our survey, a necessary balance was struck between brevity and description for each curricular topic.

Additionally, certain topics included in the general boot camp curriculum for all specialties were excluded from the survey for the IM-specific track. There may be a degree of recall bias and sampling bias. Four months had passed since the sampled interns graduated medical school and their recollections of medical school curricula may be error prone. We chose to administer the survey 4 months into intern year to maximize participants' ability to identify deficits from their undergraduate medical education. We believe the 4-month time-period enabled participants to have an accurate recollection of medical school curricula and the insight of an intern with substantial clinical experience. Administering the survey later may have increased the risk of recall bias or matriculation bias. Administering the survey earlier may have limited participants' clinical experience. Finally, we acknowledge the limitations inherent in a single-center study. Our interns come from 44 US medical schools, and we recognize that this is only a fraction of all the medical schools in the country. We only sampled IM interns, and therefore, we cannot generalize the results to other specialties. Next steps include evaluating our new boot camp curriculum in preparing students for residency.

\section{Compliance with Ethical Standards}

Conflict of Interest The authors declare that there is no conflict of interest.

Ethical Approval The University of Pittsburgh Institutional Review Board (IRB \#2003005) determined that this study is exempt.

Informed Consent NA

\section{References}

1. CarLee A, Rowat J, Suneja M. Assessing entrustable professional activities using an orientation OSCE: identifying the gaps. J Grad Med Educ. 2019;11(2):214-20.

2. Langdale LA, Schaad D, Wipf J, Marshall S, Vontver L, Scott CS. Preparing graduates for the first year of residency: are medical schools meeting the need? Acad Med. 2003;78(1):39-44.

3. Lypson ML, Frohna JG, Gruppen LD, Woolliscroft JO. Assessing residents' competencies at baseline: identifying the gaps. Acad Med. 2004;79(6):564-70. 
4. Pearlman RE, Pawelczak M, Tachyt AC, et al. Program director perceptions of proficiency in the core entrustable professional activities. J Grad Med Educ. 2017;9(5):588-92.

5. Angus SV, Vu TR, Willett LL. Internal medicine residency program directors' views of the core entrustable professional activities for entering residency: an opportunity to enhance communication of competency along the continuum. Acad Med. 2017;2(6):785-91.

6. Vogel L. Pre-residency boot camps calm medical graduate jitters. Can Med Assoc J. 2018;190(32):E967-8.

7. Teo AR, Harleman E, O'sullivan PS, et al. The key role of a transition course in preparing medical students for internship. Acad Med. 2011;86(7):860-5.

8. Heidemann LA, Walford E, Mack J, Kolbe M, Morgan HK. Is there a role for internal medicine residency preparation courses in the fourth year curriculum? A single-center experience. J Gen Intern Med. 2018;33(12):2048-50.

9. Wayne DB, Cohen ER, Singer BD, Moazed F, Barsuk JH, Lyons EA, et al. Progress toward improving medical school graduates' skills via a "boot camp" curriculum. Simul Healthc. 2014;9(1): 33-9.
10. Laack TA, Newman JS, Goyal DG, Torsher LC. A 1-week simulated internship course helps prepare medical students for transition to residency. Simul Healthc. 2010;5(3):127-32.

11. Fisher JW, Thompson BM, Garcia AD. Integrative clinical experience: an innovative program to prepare for internship. Teach Learn Med. 2007;19(3):302-7.

12. Kern DE. Curriculum development for medical education: a six step approach. Baltimore: Johns Hopkins University Press; 1998.

13. Lyss-Lerman $\mathrm{P}$, Teherani $\mathrm{A}$, Loeser $\mathrm{H}$, et al. What training is needed in the fourth year of medical school? Views of residency program directors. Acad Med. 2009;84:823-9.

14. Angus $\mathrm{S}, \mathrm{Vu} \mathrm{TR}$, Halvorsen AJ, Aiyer M, McKown K, Chmielewski AF, et al. What skills should new internal medicine interns have in July? A national survey of internal medicine residency program directors. Acad Med. 2014;89(3):432-5.

Publisher's Note Springer Nature remains neutral with regard to jurisdictional claims in published maps and institutional affiliations. 